\title{
Theoretic Investigation on “Open-type” PE Teaching Mode
}

\author{
Yanyan Li \\ Xi'an International University, Xi’an, Shaanxi, 710077
}

Keywords: open-type PE teaching mode, physical education, present teaching situation, instructional theory.

\begin{abstract}
It's an important assignment for contemporary physical educators to concern on the theory of open-type PE teaching mode and explore the implementation of it. Applying the open-type PE teaching mode to build an open sports platform for students, does benefit the all-round improvement of contemporary students' physical quality. The paper is based on the present situation of physical teaching and mainly analyzes the open-type PE teaching mode.

With the rapid development of social civilization, the physical exercise has gradually become a significant social activity. Nowadays, physical education developing rapidly, the education department and the public ask higher requirements to physical educator. To promote the physical education's innovation, it's necessary to explore new teaching mode actively on the basic of existing physical educating experience and summary more scientific theories of education. The open-type PE teaching mode conducts the innovation of physical education.
\end{abstract}

\section{The analysis of open-type PE teaching mode's composition}

Every teaching mode has a scientific educational guiding ideology. For open-type PE teaching mode, it's people-oriented educating principle. The people-oriented principle cares every student's growth and values the joy and the sense of achievement they gain in physical learning activities. The skills students get and master at physical learning activities are directly infected by the students' emotion on the activities. If students regard physical activities and physical learning as a treat, then they will be willing to take part in activities as well as have a more efficient command of physical skills taught by teachers. But if they regard it as a dull, boring, tired and suffering thing, they will have trouble in cooperating perfectly with teachers in the activities, only to pretending learning, resulting in a big decline on the physical learning efficiency. However, the open-type PE teaching mode sets the people-oriented principle as the guiding ideology. And under the thought's guidance, the mode actively reforms both teaching contents and teaching environments. It makes much of students' dominant position in physical learning and allows teacher to extend the content to build a more relaxed and happier learning environment. Under the guidance of the principle, the open-type PE teaching mode enables students get the pleasure of PE, helps more students develop good habit of physical exercise and accelerates the achievement of the objective of physical education.

The objective of PE teaching activities is comprehensive. It consists of five areas, which are the cultivation of students' participating awareness, the improvement of sports skills, mental health, physical health and the ability of social adaptation. According to the statistics of students ' physical fitness test in recent years, our students ' physical fitness levels decreased obviously. Shorted in consciousness of physical exercise, students' health goes bad distinctly, reflecting the serious problem that parts of educational aims in physical education do not come true. Physical education is as the same as other subjects' education, undertaking the vital responsibilities to grow socialist constructors. But in the practical physical education activities, many physical educator don't pay attention to the cultivation of students' physical participating awareness, ignored the improvement of students ' physical and mental health and little emphasize students ' social adapting ability training. They only pay attention to raising the level of skills, only to enhance teaching professionally and weaken the students ' interest in sports. Get out of the traditional PE teaching 
mode, get away from the rigid pattern of athletic teaching, infusion, exam-oriented teaching, focus on students ' physical and mental health, only then can we make the physical education activities alive and get the teaching to be more meaningful.

Promoting students ' physical and mental health is the chief objective of physical education activities. And the physical education activities is an important approach to improve students ' physical and mental health. Making use of diverse sports activities to help students improve their personal fitness, is the foundational goal of physical education activities. Open-type PE teaching mode thinks highly of the status of athletic teaching content, more of the function of leisure and health teaching content. Combining traditional courses' contents by absorbing the quintessence, discarding the dross and integrating new teaching content is the actual performance of the open characteristic of open-type PE teaching mode. Enabling traditional athletics, modern leisure and health-oriented physical education teaching contents to meet the needs of different students' physical exercises and students to persist in doing exercise in entertaining sports activities is capable to promote the role of physical education play. In each of physical education curriculum, as long as students favor it, it will be possible to call the students' enthusiasm of physical exercises, having them participate in sports activities. Only when students actively participate in sports activities, can the role of physical education play.

Open-type PE teaching model differs from traditional PE teaching mode in the teaching program. The open-type is unlimited in all, no matter members, course contents students select, project of learning physical education, time and venue for learning.

First, members is unlimited. In campus's open-type PE teaching activities in schools, the participants is not merely limited in teachers and students, but also welcome to other educating staff to participate in sports activities. The open-type is a required course for underclassmen, and the senior can join the physical education activities through selecting their favorite sports project in the elective system. In the open-type PE teaching activities, the teacher can choose to participate in PE class, who involves local teachers, teacher supernumeraries and other schools' talented teachers. Meanwhile, the school can also encourage graduates, instructors, workers in school restaurants, shop owners and staff and retired school employees to be involved in sports activities. With unlimited sports members, it can enlarge the groups, stimulate every learner's desire to sports, form a good physical learning environment, provide students with greater sports learning arena, influence the communication between teachers and students and embolden teachers talk about business in the physical training activities, share their teaching experience and utilize the open-type PE teaching activities to strength the power of school in many cases.

Second, time is unlimited. Unlimited physical learning time, apart from PE arrangement in curriculum, time, enables to involve students' free time of the morning and night, weekends and holidays into the present sport system. The increase of students' learning opportunities allows students and teachers to have lessons during the time of fewer learning tasks or more energetic. With the use of unlimited sports teaching time, it enables students to improve their time's flexibility, physical teachers to pay more with more rewards. Encouraging teachers' time and students' to agree to do physical education planning helps to upgrade the efficiency of PE teaching.

Third, venue is unlimited. Schools should have eyes on the prolonging of opening hours in gym neither indoor nor outdoor. Making good use of the valid transitions of the daytime and the evening time enables students to have the chance to go into the venue to do sports at any time throughout the whole day. Participants in different sports activities have different needs on site, so except the exclusive athletic field for school professional athletes, other sites can be occupied as sports venues. Students can select the individual class site under the consideration of the private economy level and physical exercise needs. Moreover, the school needs to make reasonable venue rental charges standards for physical education venues to properly reduce the economic pressure for students.

\section{The analysis of the open-type PE teaching mode's implementation strategy}

In order to apply the open-type PE teaching mode to the practical teaching work, the school's education administrators have to establish alternative consciousness and awareness of service. 
When instructing the all-new PE teaching mode, the competent authority should provide convenience for educators and lead them to change competitive patterns of physical education. On the reform of physical education activities, physical education administrators should survey on students' sports learning interest, comprehend the students demands on physical education class and do some appropriate reforms on traditional sports projects founded on students' interests. Only when school's education administrators admit the open-type PE teaching mode, change the teaching staff, the location, course content under the guidance of personal alternative awareness , show willing to serve student, can the implementation of the mode be facilitated.

Applying the open-type PE teaching mode to implement teaching is undoubtedly a big challenge for physical educators. Therefore, teachers should be in conjunction with the characteristic of new teaching mode, start from the primary one and make before-class preparations. Under the open-type teaching mode, a physical educators may have to teach many sports simultaneously, so physical teachers should take an active part in improving the professional ability of personal physical teaching, while actively get in touch with new sports projects. Before teaching, teachers need to be familiar with the content of each class as well as the learning level and physical fitness level of participants in sports activities. Moreover, they should enrich their knowledge reserve with the combination of both science and competence in profession filed of physical education. In the open-type PE teaching class, teachers should introduce the relevant of sports, show students the physical skills and help students lift doubts and improve their learning outcomes with the use of extensive training activities. In advance of the physical education, teachers should formulate attendance rules, make good attendance record, and do promotion of the science of open-type PE teaching activities.

Embolden students to select their favorite PE project and teacher and accordant class time and location in the elective system is the prerequisite to do well in the open-type PE teaching work. Only when the student get a tip of succeeding in selecting class, can he go to learn in his selected class. The PE class can practice a lot. Besides the theory study, students are demanded to participate much to improve personal physical skills. Hence, teacher can encourage students make a different choice on PE practice class every time, so they can have a better command on their physical learning features and have certainty on the best matching exercise by means of multiple choices and diverse participation. When leading students to select PE learning project, teacher should embolden students to challenge themselves and make brave attempts. Nevertheless, different PE project, different examine approval. The highlight of test is best for students physical fitness. After students finish courses, if passing, award a certificate for good health or improving healthy level, contributing to getting the open-type PE learning activities approved by students, welcomed by students and extending in a wide scale.

\section{Conclusion}

According to the above-mentioned, compared to the traditional PE teaching mode, the open-type have obvious edges. The innovation of physical education teaching doesn't greatly increase until lessen the limitations of the physical education teaching activities and open teachers' physical education thinking. Besides, develop and broaden on the theoretical connotation of open-type PE teaching mode, studying new educational theories hard, practice under the leadership of accurate and scientific education ideology, only then can physical education activities satisfy the developmental requirement of students, can physical education objectives come to a fact.

\section{References}

[1] Songtao Li, The construction of PE teaching mode under Idea of “Primordial”[j], Teaching and Management, 18,2012

[2] Xiaobin Xu, Dynamic PE teaching mode's construction and practice research [j], Journal of Shenyang Sports University,02, 2011 
[3] Xian Chen. Construct open-type PE class and animate the sports class[j], New Courses (Teens), 01, 2009

[4] Jiujian Cui, The study of infection social transformation on the development of physical education in vocational high schools and its countermeasures[j], Jiangsu science and technology information,29,2016

[5] Lunhui Li, The theoretic and practice study based on the theory of innovation education in physical education teaching method[j], Human Resources Development,16, 2016

[6] Yujin Wang, The Investigation on implementing the open-type PE teaching mode[j]. Sport mentorship, 04, 2007

[7] Zhaozhong Zhong, Selection and application on teaching mode of PE class[j], Career, 4, 2007

[8] Jianxin $\mathrm{Xu}$, Reflections on constructing service-oriented teaching pattern in PE class[j], New Courses Studying (Elementary Education), 11, 2009 